\title{
JADARA
}

Volume 3 Number 3

Article 4

November 2019

\section{Convention Announcement}

None None

None

Follow this and additional works at: https://repository.wcsu.edu/jadara

\section{Recommended Citation}

None, N. (2019). Convention Announcement. JADARA, 3(3). Retrieved from https://repository.wcsu.edu/ jadara/vol3/iss3/4 


\title{
ANNOUNCING
}

\author{
the Third \\ CONVENTION
}

of

\author{
Professional Rehabilitation Workers \\ with the Adult Deaf \\ October 11 - 14, 1970 \\ Flagship Rochester Hotel \\ Rochester, New York
}

